\title{
The effect of acute simvastatin administration on the severity of arrhythmias resulting from ischaemia and reperfusion in the canine: Is there a role for nitric oxide?
}

\author{
Gábor Kisvári ${ }^{a}$, Mária Kovács ${ }^{a}$, János Gardi ${ }^{\text {b }}$, Gyorgy Seprényi ${ }^{\text {, }}$, \\ József Kaszaki ${ }^{\mathrm{d}}$, Ágnes Végh ${ }^{\mathrm{a}, *}$ \\ ${ }^{a}$ Departments of Pharmacology and Pharmacotherapy, University of Szeged, Albert-Szent Gyo rgyi Medical Centre, Szeged, Hungary \\ ${ }^{\mathrm{b}}$ First Internal Medicine, University of Szeged, Albert-Szent Gyo rgyi Medical Centre, Szeged, Hungary \\ ${ }^{\mathrm{c}}$ Medical Biology, University of Szeged, Albert-Szent Gyo rgyi Medical Centre, Szeged, Hungary \\ ${ }^{\mathrm{d}}$ Institute of Surgical Research, University of Szeged, Albert-Szent Gyo rgyi Medical Centre, Szeged, Hungary
}

\section{A R T I C L E I N F O}

\section{Article history:}

Received 10 December 2013

Received in revised form

14 March 2014

Accepted 21 March 2014

Available online 28 March 2014

Keywords:

Simvastatin

Nitric oxide

Ischaemia/reperfusion

Arrhythmias

\begin{abstract}
A B S T R A C T
The present study has examined the effects and the possible mechanisms of a single dose of simvastatin on the severity of arrhythmias resulting from a 25 min occlusion and reperfusion of the left anterior descending coronary artery in anaesthetized (chloralose and urethane) dogs. The control animals $(n=16)$ were given the solvent of simvastatin by slow (over $5 \mathrm{~min}$ ) intracoronary (ic.) injection just prior to the occlusion. Twenty-six dogs were treated with simvastatin $(0.1 \mathrm{mg} / \mathrm{kg})$ by the same route, both in the absence $(n=15)$ and in the presence $(n=11)$ of L-NAME. This latter was administered ( $5 \mathrm{mg} / \mathrm{kg}$, ic.) either alone $(n=12)$ or $10 \mathrm{~min}$ before the simvastatin treatment. The severity of ischaemia (epicardial STsegment, inhomogeneity) and ventricular arrhythmias (ventricular premature beats [VPBs], ventricular tachycardia [VT] and fibrillation [VF]), plasma nitrite/nitrate levels, myocardial superoxide production and eNOS activity were assessed. Compared with controls simvastatin significantly reduced the number of VPBs $(289 \pm 34$ vs. $94 \pm 25)$ and the episodes of VT ( $5.6 \pm 1.3$ vs. $0.3 \pm 0.2)$, the incidence of VT ( $88 \%$ vs. $20 \%$ ) and VF ( $56 \%$ vs. $0 \%$ ) during occlusion and increased survival (0\% vs. $33 \%$ ) on reperfusion. There were also less marked ischaemic changes in the simvastatin-treated dogs than in the controls. Simvastatin preserved eNOS activity and nitric oxide (NO) bioavailability during occlusion and attenuated superoxide production following reperfusion. All these effects of simvastatin (except for the protection against VF) were reversed by L-NAME. We conclude that simvastatin given just prior to ischaemia/reperfusion reduces the severity of arrhythmias. This effect involves both NO-dependent and NO-independent mechanisms.
\end{abstract}

(c) 2014 Elsevier B.V. All rights reserved.

\section{Introduction}

There is increasing experimental and clinical evidence that statins, beyond their lipid lowering effects, are able to reduce the incidence of fatal ventricular arrhythmias, which are the major causes of mortality in various cardiovascular diseases (e.g. 4S Group 1994; LIPID Study Group, 1998; Horwich et al., 2004; Gould et al., 2007). Since cardioprotection by statins was also observed under normocholesterolemic conditions (Lefer et al., 1999, 2001; Chen et al., 2003; Adameová et al., 2009), it was

\footnotetext{
* Correspondence to: Department of Pharmacology and Pharmacotherapy, University of Szeged, Albert Szent-Gyorgyi Faculty of Medicine, Dóm tér 12, P.O. Box 427, H-6720, Hungary. Tel.: +36 62455 673; fax: +36 63454565.

E-mail address: vegh.agnes@med.u-szeged.hu (Á. Végh).
}

proposed that these drugs might have cholesterol-independent pleiotropic effects as well (Calabro and Yeh, 2005; Liao and Laufs, 2005). These include plaque stabilization and improvement in vascular endothelial function (O'Driscoll et al., 1997), reduction in oxidative stress-induced injury (Ceylan et al., 2003; Jones et al., 2003; Bloom et al., 2010), inhibition of inflammatory (Shimizu et al., 2003; Endres, 2006) and thrombogenic responses (Liao and Laufs, 2005). Most of these effects are thought to play a role in the anti-arrhythmic action of statins (Chen et al., 2003, 2010; Kostapanos et al., 2007; Xing et al., 2007), and would explain the observed reduction in cardiac death in patients with statin treatment (De Sutter et al., 2000; Zhao et al., 2008). The salutary effects, unrelated to the cholesterol lowering action of statins, are proposed to involve both nitric oxide (NO)-dependent and NOindependent mechanisms (Lefer et al., 2001; Wright and Lefer, 
2005). For example, statins have been found to increase the generation of NO via eNOS activation (Laufs et al., 1997, Mital et al., 2000; Landmesser et al., 2004), enhance the formation of prostanoids (Birnbaum et al., 2005) and induce heme-oxygenase-1 (Lee et al., 2004).

Perhaps, the most likely mechanism by which statins provide protection against ischaemia and reperfusion-induced arrhythmias is their ability to increase NO synthesis (Mital et al., 2000; Lefer et al., 2001; Atar et al. 2006). We have substantial previous evidence that NO plays an essential role in both the early and delayed anti-arrhythmic effects of preconditioning, induced either by brief periods of coronary artery occlusion (Végh et al., 1992b), cardiac pacing (Kis et al., 1999) or heavy physical exercise (Babai et al., 2002). We hypothesized that these preconditioning stimuli, via the activation of eNOS, enhance NO production and modify myocardial function during ischaemia and reperfusion (Parratt and Végh, 1996). More recently we showed that pacing induces an immediate increase in eNOS activation and NO production, but it also causes an up-regulation of eNOS gene and protein expressions 12 and 24 h later (Kovács et al., 2013).

So far, the proposals for mechanisms by which statins increase eNOS activity come mainly from studies with long-term statin treatment where there is sufficient time for eNOS up-regulation by stabilizing eNOS mRNA (Laufs and Liao, 1998; Lefer et al., 2001). There are, however, only a few studies which have attempted to examine the acute effects of statins; these were related to the assessment of infarct size (Tiefenbacher et al., 2003; Wolfrum et al., 2004; Carnická et al., 2011) and post-ischaemic contractile dysfunction (Szárszoi et al., 2008). Taking these studies into account and considering the fact that eNOS can rapidly be activated by a preconditioning stimulus, we assumed that statins may also have an acute effect on arrhythmias, which involves the activation of eNOS. This was studied in our established canine model of ischaemia and reperfusion by the application of a single bolus injection of simvastatin.

\section{Materials and methods}

\subsection{Animals and surgical preparation}

Adult mongrel dogs of both sexes with a mean body weight of $23 \pm 1 \mathrm{~kg}$ were used. The origin and upkeep of these dogs were in accord with Hungarian law (XXVIII, chapter IV, paragraph 31) regarding large experimental animals which conforms with the Guide for the Care and Use of Laboratory Animals published by the US National Institutes of Health (NIH Publication No. 85-23, revised 1996). Under light anaesthesia (30 mg/kg intravenous sodium pentobarbitone, Sigma, St. Louis, MO, USA) the right femoral artery was prepared and catheterized, through which the dogs were further anaesthetized with a mixture of chloralose and urethane (60 and $200 \mathrm{mg} / \mathrm{kg}$, respectively; Sigma, St. Louis, MO, USA) to maintain anaesthesia. The animals were then intubated and ventilated with room air using a Harvard respirator (Harvard Apparatus, Natick, MA, USA) at a rate and volume sufficient to maintain arterial blood gases and $\mathrm{pH}$ within physiological limits (Végh et al., 1992a). Body temperature was measured from the mid-oesophagus and maintained by a heating pad at $37 \pm 0.5^{\circ} \mathrm{C}$.

Polyethylene catheters were inserted into the right femoral artery for monitoring arterial blood pressure (systolic and diastolic), and via the left carotid artery into the left ventricle (LV) for the measurement of systolic (LVSP) and end-diastolic (LVEDP) pressures. From the LV pressure curves changes in positive and negative $\mathrm{dP} / \mathrm{dt}_{\max }$ were calculated.
The chest was opened at the fifth intercostal space and the anterior descending branch of the left coronary artery (LAD) was prepared for occlusion just proximal to the first main diagonal branch. Distal to the occlusion site a smaller side branch of the same artery was also prepared and cannulated for the local administration of drugs (simvastatin and L-NAME) and vehicle. Another catheter was positioned through the right jugular vein into the coronary sinus to obtain blood samples for the assessment of plasma nitrate/nitrite (NOx) levels. In some dogs from each group, the left circumflex (LCX) coronary artery was also prepared to measure coronary blood flow ( $\mathrm{CBF} ; \mathrm{ml} / \mathrm{min}$ ) by means of a transit time Doppler flow probe (Hugo Sachs Electronics, Germany).

The severity of myocardial ischaemia was evaluated by changes in the epicardial ST-segment and in the degree of inhomogeneity of electrical activation. These were measured by a composite electrode (containing also four unipolar electrodes by which changes in ST-segment [mV] were detected) positioned within the potentially ischaemic area as described previously (Végh et al., 1992a). The greatest delay in activation within the ischaemic area following coronary artery occlusion was expressed in ms. All parameters, together with a chest lead electrocardiogram, were measured with a Plugsys Haemodynamic Apparatus (Hugo Sachs Electronics, Germany) and recorded on a Graphtec Thermal Array Recorder (Hugo Sachs Electronics, Germany).

Ventricular arrhythmias were assessed according to the Lambeth conventions (Walker et al., 1988) with that modification as outlined previously (Végh et al., 1992a). In brief, the total number of ventricular premature beats (VPBs), the incidence and the number of episodes of ventricular tachycardia (VT; defined as a run of four or more consecutive VPBs at a rate faster than the resting heart rate), and the incidence of ventricular fibrillation (VF) were assessed during the occlusion period. During reperfusion, only the incidence of VF, which is a fatal event in this species, was determined. Dogs that were alive 1-2 min after reperfusion were considered to be survivors.

The risk area following coronary artery occlusion was assessed by injecting Patent Blue $\mathrm{V}$ dye into the re-occluded artery using the same method that has been described in detail elsewhere (Végh et al., 1992a).

\subsection{Measurement of plasma nitrate/nitrite (NOx) levels}

These were performed as described previously (Kiss et al., 2010). Plasma nitrate/nitrite $\left(\mathrm{NO}_{x}\right)$ concentrations were determined by means of the Griess reaction in blood samples taken from the coronary sinus at various time intervals as illustrated in Fig. 1. After preparation of blood samples, the absorbance of the azo compound was measured spectrophotometrically at a wavelength of $540 \mathrm{~nm}$ and the total nitrate/nitrite $\left(\mathrm{NO}_{x}\right)$ concentration ( $\mu \mathrm{mol} / \mathrm{l}$ ) was determined using a standard calibration curve of $\mathrm{NaNO}_{2}$ and $\mathrm{NaNO}_{3}$ (Sigma, St Louis, MO, USA).

\subsection{Determination of eNOS phosphorylation by western blot}

Freshly excised tissue samples from the ischaemic and nonischaemic regions of the left ventricular myocardial wall were immediately frozen in liquid nitrogen and stored at $-80^{\circ} \mathrm{C}$. The samples were prepared as described previously (Gonczi et al., 2012; Kovács et al., 2013). In brief, $100 \mu \mathrm{g}$ of protein extracts were resolved using $8 \%$ sodium dodecyl sulphate-polyacrylamide gel electrophoresis and blotted on polyvinylidene fluoride membranes. The blots were immunolabeled overnight with a monoclonal mouse anti-eNOS primary antibody (pS1177, BD Biosciences) diluted to $1: 2500$, followed by $1 \mathrm{~h}$ incubation with an HRP-conjugated anti-mouse rabbit secondary antibody (Dako, 


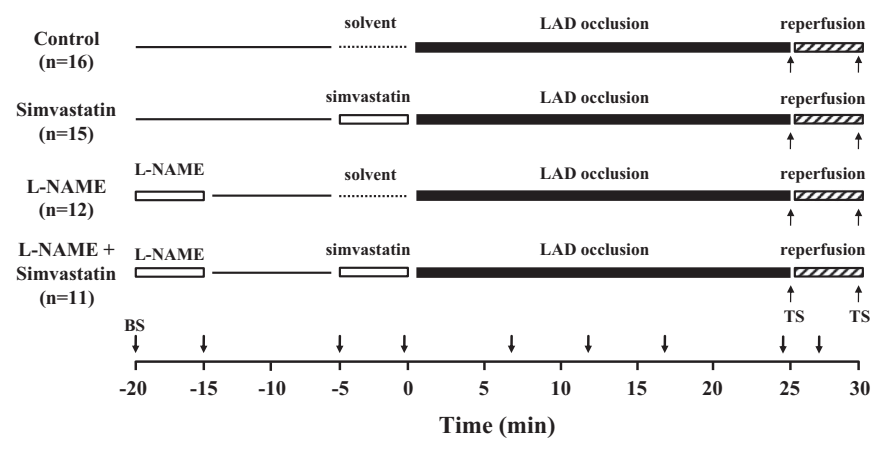

Fig. 1. Experimental protocol. Four groups of dogs were used. After $20 \mathrm{~min}$ recovery from surgery the control dogs $(n=16)$ were received the solvent of simvastatin in slow (over $5 \mathrm{~min}$ ) intracoronary (ic.) bolus injection just prior to a 25 min occlusion of the left anterior descending (LAD) coronary artery. In 26 dogs activated simvastatin was administered in a dose of $0.1 \mathrm{mg} / \mathrm{kg}$ by the same route. In 11 out of these 26 animals the NOS inhibitor L-NAME ( $5 \mathrm{mg} / \mathrm{kg}$, ic.) was also administered $10 \mathrm{~min}$ before the simvastatin treatment. In another group of dogs $(n=12)$ only L-NAME was given. All these dogs were subjected to LAD occlusion with or without ( $n=5$ or 6 dogs in each group) a subsequent rapid reperfusion. During the experiments blood samples (BS) were taken at various time intervals (indicated by arrows) from the coronary sinus to determine plasma nitrite/nitrate $\left(\mathrm{NO}_{x}\right)$ levels. Myocardial tissue samples (TS) were also collected at the end of the ischaemic period or $5 \mathrm{~min}$ after reperfusion for further biochemical analyses.

Danmark) in a dilution of 1:8000. Band densities were detected with the ECL Plus kit (GE Healthcare, Buckinghamshire, UK) and developed on Amersham Hyperfilm ${ }^{\mathrm{TM}}$ (GE Healthcare, Buckinghamshire, UK). Pixel intensities of each band were measured using ImageJ software (NIH). Three parallel Western blots were performed for the statistical analysis using Bonferroni correction. For the verification of equal loading, PVDF membranes were labelled with Coomassie Blue. The amount of phosphorylated eNOS (peNOS) in all groups was compared to the amount of peNOS obtained in the sham-operated controls.

\subsection{Determination of the functional activity of eNOS by radio immunoassay}

This was performed using a NOS activity assay kit (Cayman Chemical, Ann Arbor, MI, USA) based on the biochemical conversion of $\left[{ }^{3} \mathrm{H}\right]$ L-arginine to $\left[{ }^{3} \mathrm{H}\right]$ L-citrulline by NOS. From the tissue samples $(100 \mathrm{mg}$ ) membrane proteins were isolated, homogenized in ice-cold homogenization buffer (Cayman Chemical, Ann Arbor, MI, USA), and centrifuged at $2000 \mathrm{~g}$ for $15 \mathrm{~min}$. The supernatant was then ultra-centrifuged at 50,000 g for $45 \mathrm{~min}$ and the pellet (membrane fraction) was re-suspended in the homogenization buffer. A liquid scintillation counter was used to determine eNOS activity by measuring the amount of the radio-labelled citrulline formed during the reaction, and expressed as the percentage of the total counts corrected with the background counts per minute.

\subsection{Assessment of superoxide production}

This was determined by dihydroethidium (DHE; SigmaAldrich) fluorescence staining as described previously (Kiss et al., 2010). Briefly, tissue blocks, excised from the ischaemic myocardial wall were embedded in optimal cutting temperature compounds. Cryosections $(20 \mu \mathrm{m})$ were produced, stained with DHE $(1 \mu \mathrm{mol} / \mathrm{l}$, dissolved in $\mathrm{pH} 7.4$ phosphate buffer solution), and incubated at $37{ }^{\circ} \mathrm{C}$ for $30 \mathrm{~min}$ in a dark humidified chamber. A negative control was obtained by blocking the reaction with N-acetyl-L-cysteine (NAC, $100 \mathrm{mmol} / \mathrm{l}$, Sigma-Aldrich). Both from the stained and the negative control samples 10 to 15 serial images were captured by a confocal laser scanning microscope (Olympus FV1000).
The intensity of the fluorescent signals were analysed by Image software (NIH) and expressed in arbitrary units.

\subsection{Preparation of simvastatin solution}

Before the application of simvastatin (Sigma, St Louis, MO, USA) it has to be converted into an active form. A stock solution containing $25 \mathrm{mg}$ simvastatin, dissolved in $625 \mu \mathrm{l}$ ethanol and $937.5 \mu \mathrm{l} 0.1 \mathrm{~N} \mathrm{NaOH}$, was prepared and incubated at $50{ }^{\circ} \mathrm{C}$ for $2 \mathrm{~h}$. Then the $\mathrm{pH}$ of the solution was adjusted to 7.0 with $1 \mathrm{~N} \mathrm{HCl}$ and stored at $-20{ }^{\circ} \mathrm{C}$ until use. Immediately prior to the experiments an aliquot was taken and diluted in distilled water to obtain the appropriate dose.

\subsection{Experimental protocol}

Dogs were randomly selected to form four experimental groups (Fig. 1). Control dogs $(n=16)$ were administered the solvent of simvastatin $(0.5 \mathrm{ml} / \mathrm{min})$ in intracoronary injection (over $5 \mathrm{~min}$ ) and subjected to a 25 min occlusion and then reperfusion of the descending branch of the left coronary artery (LAD). Fifteen dogs were received activated simvastatin in a dose of $0.1 \mathrm{mg} / \mathrm{kg}$ by the same route, $5 \mathrm{~min}$ prior to the onset of the occlusion. In another two groups, L-NAME (Sigma) was given in a dose of $5 \mathrm{mg} / \mathrm{kg}$ also in slow intracoronary injection, 15 min before the solvent (L-NAME; $n=12)$ and the simvastatin $(n=11)$ administration. At the end of the experiments the hearts were stopped by an excess of the anaesthetic, and myocardial tissue samples were collected from both the ischaemic and the non-ischaemic regions of the left ventricular wall for further analyses. In at least 5 dogs of each group sample taking was performed at the end of the $25 \mathrm{~min}$ occlusion period, whereas in dogs that had been subjected to reperfusion, tissue samples were collected either 5 min after reperfusion (these animals were considered as survivors) or at the time when the fibrillation was observed.

\subsection{Statistical analysis}

All data are expressed as means \pm S.E.M. and the differences between means were compared by ANOVA for repeated measures and by the one-way ANOVA as appropriate, using the Fisher post hoc test. VPBs and episodes of VT were compared using the Kruskal-Wallis test. The incidences of arrhythmias (such as VT and VF) and survival from the combined ischaemia and reperfusion insult were compared by the Fisher's exact test. Differences between groups were considered significant at $P<0.05$.

\section{Results}

3.1. Haemodynamic changes following the administration of solvent, simvastatin and ${ }_{L}-N A M E_{2}$ as well as after coronary artery occlusion

These are summarized in Table 1 and Table 2. Local intracoronary injection of simvastatin and the solvent of simvastatin did not substantially modify the haemodynamic parameters and blood flow, measured on the LCX coronary artery. In contrast, the administration of L-NAME significantly elevated arterial blood pressure and reduced heart rate without substantially modifying the other haemodynamic parameters (Table 1). These haemodynamic changes in the L-NAME treated dogs were still present before the onset of the LAD occlusion.

Occlusion of the LAD resulted in significant reductions in arterial blood pressure, LVSP, positive and negative $\mathrm{dP} / \mathrm{dt}_{\max }$ and an increase in LVEDP, whereas the HR remained substantially unchanged. These alterations were almost similar in all the 
Table 1

Haemodynamic changes following the administration of solvent, simvastatin and L-NAME.

\begin{tabular}{|c|c|c|c|c|c|c|}
\hline & \multicolumn{2}{|l|}{ Solvent } & \multicolumn{2}{|l|}{ Simvastatin } & \multicolumn{2}{|l|}{ L-NAME } \\
\hline & Baseline & Change & Baseline & Change & Baseline & Change \\
\hline SABP (mmHg) & $140 \pm 10$ & $3 \pm 3$ & $148 \pm 8$ & $-4 \pm 2$ & $149 \pm 7$ & $19 \pm 5^{a}$ \\
\hline DABP (mmHg) & $105 \pm 6$ & $0 \pm 5$ & $101 \pm 5$ & $-2 \pm 2$ & $104 \pm 5$ & $29 \pm 5^{\mathrm{a}}$ \\
\hline MABP (mmHg) & $117 \pm 6$ & $1 \pm 4$ & $117 \pm 6$ & $-3 \pm 2$ & $119 \pm 5$ & $25 \pm 4^{a}$ \\
\hline LVSP (mmHg) & $154 \pm 8$ & $3 \pm 3$ & $158 \pm 8$ & $0 \pm 2$ & $164 \pm 7$ & $13 \pm 4^{a}$ \\
\hline LVEDP (mmHg) & $4.6 \pm 0.7$ & $0.2 \pm 0.3$ & $5.6 \pm 0.4$ & $0 \pm 0.3$ & $5.1 \pm 0.7$ & $0.4 \pm 0.3$ \\
\hline$+\mathrm{dP} / \mathrm{dt}(\mathrm{mmHg} / \mathrm{s})$ & $2316 \pm 225$ & $99 \pm 61$ & $2795 \pm 219$ & $-67 \pm 118$ & $2444 \pm 242$ & $-124 \pm 189$ \\
\hline$-\mathrm{dP} / \mathrm{dt}(\mathrm{mmHg} / \mathrm{s})$ & $2092 \pm 260$ & $91 \pm 103$ & $2415 \pm 183$ & $-107 \pm 81$ & $2172 \pm 122$ & $-43 \pm 43$ \\
\hline HR (beats/min) & $166 \pm 9$ & $5 \pm 2$ & $173 \pm 5$ & $-3 \pm 1$ & $181 \pm 8$ & $-15 \pm 3$ \\
\hline mean $\mathrm{CBF}_{\mathrm{LCX}}(\mathrm{ml} / \mathrm{min})$ & $30 \pm 1$ & $1 \pm 1$ & $30 \pm 2$ & $2 \pm 1$ & $32 \pm 2$ & $-3 \pm 2$ \\
\hline
\end{tabular}

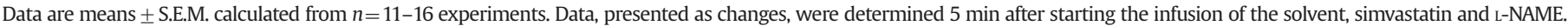

${ }^{\text {a }} \mathrm{P}<0.05$ compared to baseline value. SABP, systolic arterial blood pressure; DABP, diastolic arterial blood pressure; MABP, mean arterial blood pressure; LVSP, left ventricular systolic pressure; LVEDP, left ventricular end-diastolic pressure; HR, heart rate; CBF, coronary blood flow.

Table 2

Haemodynamic changes during a 25 min occlusion of the LAD.

\begin{tabular}{|c|c|c|c|c|c|c|c|c|}
\hline & \multicolumn{2}{|l|}{ Solvent } & \multicolumn{2}{|l|}{ Simvastatin } & \multicolumn{2}{|l|}{ L-NAME } & \multicolumn{2}{|c|}{ L-NAME + Simvastatin } \\
\hline & Baseline & Max.change & Baseline & Max. change & Baseline & Max.change & Baseline & Max.change \\
\hline SABP (mmHg) & $143 \pm 10$ & $-11 \pm 2^{\mathrm{a}}$ & $145 \pm 6$ & $-10 \pm 2^{\mathrm{a}}$ & $166 \pm 5$ & $-8 \pm 2^{a}$ & $163 \pm 8$ & $-10 \pm 3^{a}$ \\
\hline DABP (mmHg) & $104 \pm 6$ & $-11 \pm 3^{a}$ & $99 \pm 3$ & $-7 \pm 2^{\mathrm{a}}$ & $133 \pm 4$ & $-8 \pm 3^{a}$ & $129 \pm 7$ & $-11 \pm 3^{a}$ \\
\hline MABP (mmHg) & $117 \pm 6$ & $-12 \pm 3^{a}$ & $114 \pm 4$ & $-7 \pm 2^{\mathrm{a}}$ & $144 \pm 5$ & $-8 \pm 3^{a}$ & $142 \pm 8$ & $-11 \pm 2^{a}$ \\
\hline LVSP (mmHg) & $144 \pm 11$ & $-10 \pm 3^{a}$ & $145 \pm 7$ & $-9 \pm 2^{\mathrm{a}}$ & $177 \pm 5$ & $-9 \pm 2^{\mathrm{a}}$ & $180 \pm 11$ & $-14 \pm 5^{a}$ \\
\hline LVEDP (mmHg) & $4.7 \pm 0.7$ & $9.2 \pm 1.5^{\mathrm{a}}$ & $5.5 \pm 0.3$ & $8.5 \pm 1.0^{\mathrm{a}}$ & $5.5 \pm 0.7$ & $10.0 \pm 2.1^{\mathrm{a}}$ & $5.0 \pm 0.5$ & $9.0 \pm 1.0^{\mathrm{a}}$ \\
\hline$+\mathrm{dP} / \mathrm{dt}(\mathrm{mmHg} / \mathrm{s})$ & $2236 \pm 212$ & $-568 \pm 99^{a}$ & $2670 \pm 164$ & $-499 \pm 137^{a}$ & $2252 \pm 174$ & $-553 \pm 165^{a}$ & $2526 \pm 317$ & $-566 \pm 109^{a}$ \\
\hline$-\mathrm{dP} / \mathrm{dt}(\mathrm{mmHg} / \mathrm{s})$ & $2183 \pm 253$ & $-338 \pm 161^{a}$ & $2349 \pm 145$ & $-378 \pm 68^{\mathrm{a}}$ & $2197 \pm 174$ & $-491 \pm 125^{a}$ & $2317 \pm 205$ & $-350 \pm 76^{\mathrm{a}}$ \\
\hline HR (beats/min) & $171 \pm 9$ & $5 \pm 5$ & $170 \pm 4$ & $5 \pm 3$ & $166 \pm 9$ & $3 \pm 4$ & $174 \pm 11$ & $7 \pm 2$ \\
\hline mean $\mathrm{CBF}_{\mathrm{LCX}}(\mathrm{ml} / \mathrm{min})$ & $31 \pm 2$ & $9 \pm 2$ & $30 \pm 2$ & $10 \pm 2$ & $29 \pm 1$ & $9 \pm 1$ & $30 \pm 2$ & $8 \pm 2$ \\
\hline
\end{tabular}

Data are means \pm S.E.M. calculated from $n=11-16$ experiments.

a $P<0.05$ compared to baseline value. SABP, systolic arterial blood pressure; DABP, diastolic arterial blood pressure; MABP, mean arterial blood pressure; LVSP, left ventricular systolic pressure; LVEDP, left ventricular end-diastolic pressure; HR, heart rate; CBF, coronary blood flow.

examined groups. The compensatory blood flow changes, occurring on the LCX when the LAD was occluded, were not significantly modified by the administration of simvastatin and L-NAME (Table 2).

\subsection{The severity of ventricular arrhythmias during a $25 \mathrm{~min}$ occlusion of the $L A D$}

This is shown in Fig. 2. In control dogs, occlusion of the LAD resulted in a high number of ventricular premature beats (VPBs: $289 \pm 34$ ) and episodes of ventricular tachycardia (VT: $5.6 \pm 1.3$ ) that occurred in $88 \%$ of these dogs. Furthermore, $56 \%$ of the dogs fibrillated during occlusion and no control dog survived reperfusion. Local administration of simvastatin, just prior to the occlusion, significantly reduced these arrhythmia types (VPBs: $94 \pm 25$, episodes of VT: $0.3 \pm 0.2$, incidence of VT: $20 \%, \mathrm{VF}: 0 \% ; P<0.05$ compared with controls) during occlusion and increased survival (33\% vs. $0 \%$ in the controls) from the combined ischaemia and reperfusion insult. Inhibition of the L-arginine-NO pathway with L-NAME did not substantially modify arrhythmia severity occurring during ischaemia and reperfusion, but it significantly attenuated the antiarrhythmic effect of simvastatin. Thus in the presence of L-NAME the number of VPBs $(438 \pm 49)$, the incidence $(100 \%)$ and number of episodes of VT $(6.8 \pm 2.9)$ were again increased in the simvastatin treated dogs, and as in the control group, no dogs survived the combined ischaemia and reperfusion insult. Interestingly, L-NAME, however, did not affect the protective effect of simvastatin against the occlusion-induced ventricular fibrillation; i.e. as with simvastatin alone, no dog fibrillated during occlusion in the L-NAME + simvastatin group.

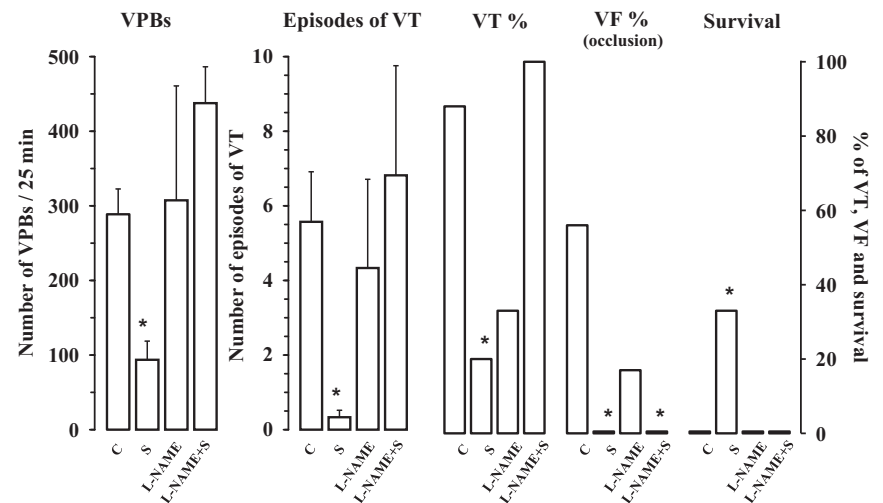

Fig. 2. The severity of ventricular arrhythmias during a 25 min occlusion and reperfusion of the LAD in control (C) and simvastatin (S) treated dogs, and also in animals given L-NAME alone or together with simvastatin (L-NAME $+\mathrm{S}$ ). A single bolus injection of simvastatin markedly reduced the numbers of ventricular premature beats (VPBs), and episodes of ventricular tachycardia (VT), the incidences of VT and ventricular fibrillation (VF) during occlusion and increased survival from the combined ischaemia and reperfusion insult. These effects of simvastatin, except for the protection against the occlusion-induced VF, were abolished by the prior administration of L-NAME. The administration of L-NAME itself did not substantially influence the severity of arrhythmias resulted from coronary artery occlusion and reperfusion. Values are means \pm S.E.M. ${ }^{*} P<0.05$ compared to the controls.

3.3. Changes in the degree of inhomogeneity of electrical activation and in epicardial ST-segment during coronary artery occlusion

These were used to assess the ischaemia severity during coronary artery occlusion. In control dogs, occlusion of the LAD 

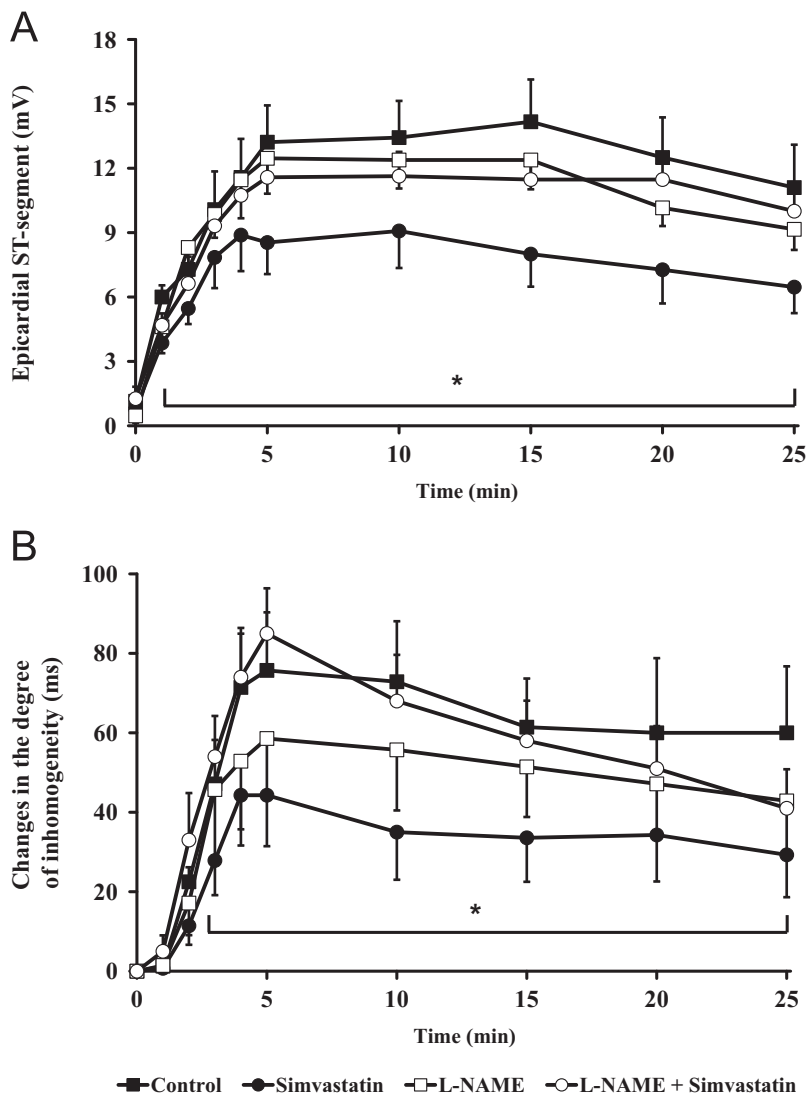

Fig. 3. Changes in epicardial ST-segment (A) and in the degree of inhomogeneity of electrical activation (B) during a 25 min occlusion of the LAD. Compared to the controls simvastatin significantly reduced these indices of ischaemia severity. These effects were attenuated by the administration of L-NAME. Values are means \pm S.E.M. ${ }^{*} P<0.05$ compared to the controls.

resulted in immediate and significant increases both in the epicardial ST-segment (Fig. 3A) and the degree of inhomogeneity of electrical activation (Fig. 3B). These changes were less pronounced in dogs treated with simvastatin. Although L-NAME itself did not modify these indices of ischaemia severity, it abolished the anti-ischaemic effects of simvastatin.

\subsection{Changes in $\mathrm{NO}_{x}$ levels during coronary artery occlusion and reperfusion}

These are shown in Fig. 4. A single bolus injection of simvastatin alone or together with L-NAME, as well as the solvent of simvastatin, did not affect the plasma $\mathrm{NO}_{x}$ levels prior to the occlusion. In contrast, the administration of L-NAME caused a slight decrease in the $\mathrm{NO}_{x}$ level, which was further declined during the occlusion. In control dogs, occlusion of the LAD resulted in a transient elevation in the plasma $\mathrm{NO}_{x}$ levels (occurring around 7 min of the ischaemia), after which they started to decrease and became significantly lower than the initial baseline values. In contrast, the administration of simvastatin elevated $\mathrm{NO}_{x}$ levels almost over the entire occlusion period. This effect was completely abolished by the prior administration of L-NAME. Reperfusion of the ischaemic myocardium evoked similar increases in $\mathrm{NO}_{x}$ levels in all groups.

\subsection{Determination of eNOS activity}

This was assessed by two ways; i.e. by the measurement of the amount of the phosphorylated form of eNOS using Western blot analysis (Fig.5A) and by the determination of the functional

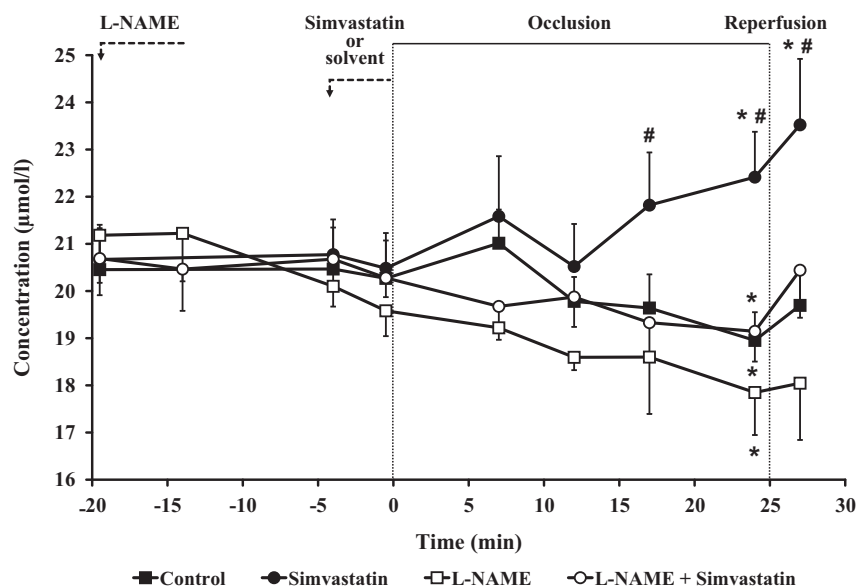

Fig. 4. Changes in plasma nitrite/nitrate $\left(\mathrm{NO}_{x}\right)$ levels in the blood of the coronary sinus. In control dogs the concentration of NO metabolites, after a transient elevation around $7 \mathrm{~min}$ of ischaemia, was significantly reduced up to end of the occlusion. In contrast, $\mathrm{NO}_{x}$ levels were maintained or even increased throughout the occlusion in the simvastatin treated dogs. L-NAME itself resulted in a decrease in the concentration of NO metabolites, and abolished the effect of simvastatin. Reperfusion caused almost similar increases of $\mathrm{NO}_{\mathrm{x}}$ in all groups. Values are means \pm S.E.M. ${ }^{*} P<0.05$ compared to the initial baseline values, and ${ }^{*} P<0.05$ compared to the control group.
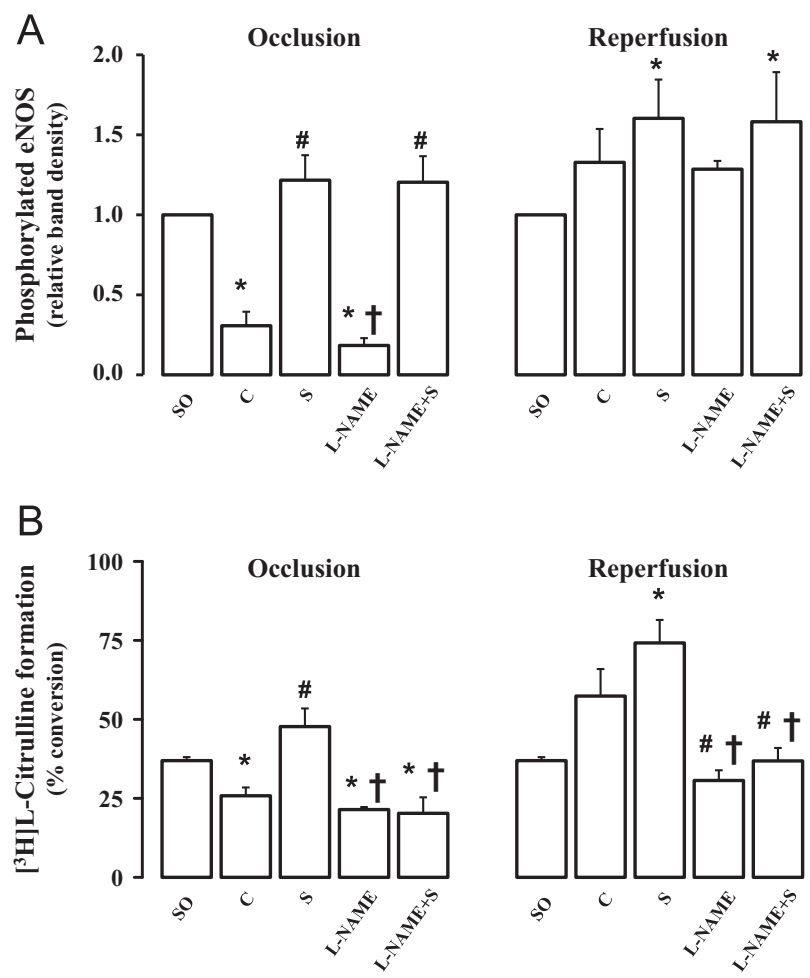

Fig. 5. Changes in the amount of phosphorylated eNOS, determined by Western blot (A) and in the functional activity of eNOS enzyme, assessed by RIA (B) in control (C) and simvastatin (S) treated dogs, and in dogs given L-NAME alone or together with simvastatin $(\mathrm{L}-\mathrm{NAME}+\mathrm{S})$. Compared to a group of sham-operated dogs (SO, $n=5$ ), a 25 min ischaemia resulted in marked decreases in eNOS activity, which was preserved or even increased in animals given a single bolus injection of simvastatin. L-NAME itself inhibited the function of eNOS (to produce NO), and abrogated the effect of simvastatin to enhance NO formation, without influencing the simvastatin-induced phosphorylation of eNOS. Simvastatin also facilitated the restoration of eNOS function during reperfusion, which effect seemed to be also L-NAME sensitive. Values are means \pm S.E.M. ${ }^{*} P<0.05$ compared to the SO group, ${ }^{\#} P<0.05$ compared to the control group, and ${ }^{\dagger} P<0.05$ compared to the simvastatin group. 
activity of eNOS using radio immunoassay (Fig. 5B). Compared to the sham-operated controls $(n=5)$, occlusion of the LAD significantly reduced the activity of eNOS, determined at the end of the 25 min occlusion period. In contrast, simvastatin preserved or even increased both the phosphorylation and the functional activity of this enzyme during occlusion. Although L-NAME given alone did not modify the ischaemia-induced reduction in eNOS activity, it inhibited the simvastatin evoked enhancement of the NO forming activity of this enzyme (Fig. 5B) without influencing the simvastatin-induced phosphorylation of eNOS (Fig. 5A), which pathway seems to be L-NAME insensitive. After such a period of ischaemia the function of eNOS was rapidly regained in the control dogs, remained elevated in the simvastatin treated animals, but it was still inhibited in dogs which were given L-NAME.

\subsection{Changes in myocardial superoxide production following reperfusion}

These are shown in Fig. 6. Compared with the sham controls, in dogs subjected to ischaemia and reperfusion a marked increase in superoxide production occurred soon after the reopening of the coronary artery. This ischaemia and reperfusion-induced generation of superoxide was significantly suppressed by the administration of simvastatin; an effect which was reversed by L-NAME.

\subsection{Changes in QTC interval following coronary artery occlusion}

This was measured in order to assess the potential direct electrophysiological effects of simvastatin. The results are illustrated in Fig. 7. In control dogs a marked increase developed in QTc interval within 5 min of the occlusion and this was maintained during the whole ischaemic period. Such a prolongation of the QTC interval was abrogated with simvastatin no matter whether L-NAME was present or not.

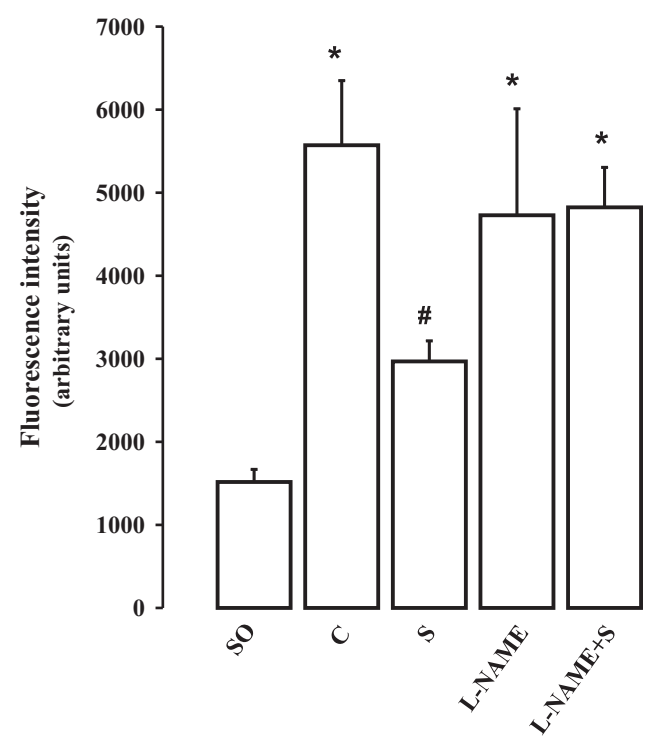

Fig. 6. Tissue superoxide production following a $25 \mathrm{~min}$ occlusion and reperfusion of the LAD in sham-operated (SO), in ischaemic control (C) and simvastatin (S) treated dogs, as well as in dogs given L-NAME alone or together with simvastatin $(\mathrm{L}-\mathrm{NAME}+\mathrm{S})$. Compared to the SO dogs, in dogs subjected to occlusion/reperfusion a significant increase in superoxide production occurred following reperfusion. This increase was markedly attenuated by the administration of simvastatin. L-NAME given alone did not modify the formation of superoxide, but it abolished the reducing effect of simvastatin. Values are means \pm S.E.M. ${ }^{*} P<0.05$ compared to the SO group and ${ }^{\#} \mathrm{P}<0.05$ compared to the control (C) group.

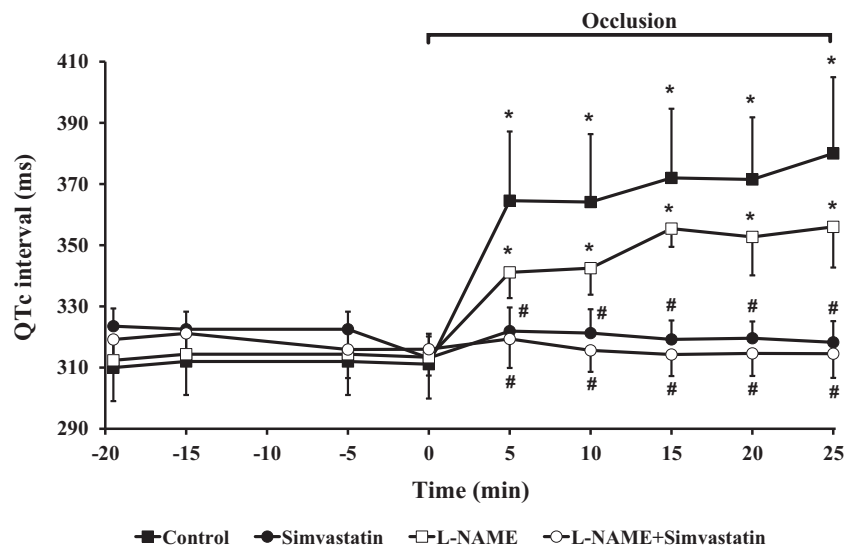

Fig. 7. Changes in the QTc interval determined prior to and during a $25 \mathrm{~min}$ occlusion of the LAD. In control dogs occlusion of the LAD resulted in a significant increase in the QTc interval, which was completely inhibited by the administration of simvastatin. L-NAME did not influence either the ischaemia-induced prolongation of QTc interval or the inhibitory effect of simvastatin. Values are means \pm S.E.M. ${ }^{*} P<0.05$ compared to the initial baseline values, and ${ }^{\#} P<0.05$ compared to the control group.

\subsection{Area at risk}

There were no significant differences in the area at risk among the groups. Thus the risk area was $38 \pm 2 \%$ in the controls, $40 \pm 3 \%$ in the simvastatin, $37 \pm 3 \%$ in the L-NAME and $39 \pm 2 \%$ in the L-NAME + simvastatin groups.

\section{Discussion}

The present study was designed to examine in an in vivo large animal model whether a single bolus injection of simvastatin is able to influence the severity of ventricular arrhythmias resulting from sudden coronary artery occlusion and reperfusion, and if so, whether this effect involves the activation of eNOS. We raised this question because the evidence that statins may reduce arrhythmias and prevent sudden cardiac death, comes mainly from studies with chronic statin treatment (e.g. Chen et al., 2003, 2010); there is much less information, apart from a few clinical studies (Kayikcioglu et al., 2003; Fonarow et al., 2005), how these drugs administered acutely would affect the consequences of ischaemia and reperfusion, including the life threatening ventricular arrhythmias (e.g. Xing et al., 2007; Carnická et al., 2011). Furthermore, since many of the beneficial effects of statins are thought to be mediated via the synthesis of nitric oxide (Laufs et al., 1997; Laufs and Liao, 1998), and since we have a number of previous evidence that NO plays an essential role in the protection against the ischaemia-induced early arrhythmias (e.g. Végh et al., 1992b; Kis et al., 1999), we have now also examined whether the effect of simvastatin on arrhythmias involves the activation of eNOS and the subsequent increase in NO formation.

The results show that in anaesthetized dogs the administration of a single dose of simvastatin markedly reduced the number of VPBs and episodes of VT, the incidence of VT and VF that resulted from a 25 min occlusion of the LAD and, compared with controls, increased survival from the combined ischaemia and reperfusion insult. This protection against arrhythmias was similar to that we have obtained previously in the same model with ischaemic preconditioning (Végh et al., 1992a), and with the administration of NO donors (Gyorgy et al., 2000; Gonczi et al., 2009; Kiss et al., 2010). Furthermore, the present study confirmed the role of eNOS activation in the antiarrhythmic effect of simvastatin, since both the phosphorylation of eNOS (determined by Western blot) and 
the functional activity of this enzyme (determined by RIA) were significantly higher during ischaemia and reperfusion in the simvastatin treated dogs than in the solvent treated controls (Fig. 5). This activation of eNOS by simvastatin certainly led to an increased generation of NO during occlusion (Fig. 4) and also to a decrease in superoxide production following reperfusion (Fig. 6). We have previous evidence that the preservation of NO bioavailability during coronary artery occlusion by preconditioning or by donating NO attenuates the reperfusion-induced marked increases of superoxide production (Kiss et al., 2010). Furthermore, the fact that L-NAME prevented the simvastatin activated enzyme to form NO (inhibits the L-arginine-NO pathway without affecting enzyme phosphorylation) and attenuated or even abolished most of the salutary effects of simvastatin, supports the hypothesis that the eNOS activated NO formation plays a crucial role in the protective effect of simvastatin against arrhythmias.

There is still ongoing debate as to whether the reduction in tachyarrhythmias (VT and VF) that are responsible in most instances for sudden cardiac death, is due to the anti-ischaemic effects of statins, or there might be a more direct electrophysiological action of these drugs, which would explain their antiarrhythmic properties. A recent review from Beri et al. (2010) has addressed this question by collecting and systematically evaluating data published over a 13-year period on the reduction of VT and VF events, as well as sudden cardiac death in patients suffering from various cardiovascular diseases and treated with statins. They concluded that the anti-arrhythmic/anti-fibrillatory effects of statins most probably result from an anti-ischaemic rather than a direct anti-arrhythmic effect, since a definitive reduction in sudden cardiac death occurred only in patients with ischaemic-type cardiovascular diseases, such as coronary artery disease or ischaemic cardiomyopathy (Beri et al., 2010). These anti-ischaemic effects of statins are supposed to mediate through nitric oxide and can indirectly influence the generation of arrhythmias (Beri et al., 2010).

Our study confirms the pronounced anti-ischaemic effect of simvastatin; the increases in the epicardial ST-segment and in the degree of inhomogeneity during occlusion were significantly less marked in the simvastatin treated dogs than in the controls. Further, this effect of simvastatin was L-NAME sensitive, since both these indices of ischaemia severity were again increased in the presence of L-NAME. However, the inhibition of eNOS only partially reversed the protective effects of simvastatin against arrhythmias. Whereas the number of VPBs and episodes of VT were significantly higher in the L-NAME + simvastatin treated dogs, the protective effect of simvastatin against the occlusion-induced VF was not affected by the administration of L-NAME. Thus similar to dogs given simvastatin alone no dog fibrillated in the L-NAME+ simvastatin group. L-NAME, however, abolished the protective effect of simvastatin against the reperfusion-induced VF. The explanations for this dichotomy could be many and varied, including differences in the underlying mechanisms of the various arrhythmia types induced by the acute ischaemia (e.g. Wit and Janse, 1992; Zipes and Wellens, 1998), as well as differences in the local and systemic regulatory influences of NO on arrhythmia mechanisms. These latter may involve, for example, the modulation of the effect of autonomic tone on the myocardium (e.g. Schwartz et al., 1995) and of gap junction function (Gonczi et al., 2009), as well as the regulation of free radical formation by NO (e.g. Iwase et al., 2007; Kiss et al., 2010).

The fact that L-NAME in the present study did not influence the protective effect of simvastatin against the occlusion-induced $\mathrm{VF}$ suggests an NO-independent and, perhaps, a more direct electrophysiological mechanism in the anti-fibrillatory effect of a single bolus injection of simvastatin. This assumption is supported by the results of the QTc interval measurements. These show that simvastatin almost completely inhibited the ischaemia-induced prolongation of the QTC interval, and this effect was not abolished by the administration of L-NAME. Although we cannot ascertain the precise mechanism of this phenomenon only from the measurement of QTc intervals, recent electrophysiological studies, however, suggest that statins influence impulse conduction, improve cardiac repolarization (Tang et al., 2007; Tekin et al., 2008), suppress cardiac excitability (Sicouri et al., 2011) perhaps by directly and selectively affecting ion channels in cardiomyocytes (e.g. Kv4.3; Su et al., 2012). Certainly, long-term statin treatment by modulating the lipid portions of the sarcolemma, which contain the ion channel regulatory proteins and signalling molecules (lipid rafts), influence the ion channel conduction and ion transport (Maguy et al., 2006; Vyas et al., 2006), but it is not known whether such a mechanism would also account for the acute administration of statins. Nevertheless, considering that polyunsaturated fatty acids, which alter the structure of the sarcolemmal phospholipids, were able to evoke immediate antiarrhythmic effect (Billman et al., 1994; Kang and Leaf, 2000; Leaf et al., 2003), we may speculate that statins perhaps also possess such acute modulator properties on the lipid portions of the membrane. This, by causing favourable changes in ion transport or by stabilizing the membrane, would lead to arrhythmia suppression during ischaemia.

In contrast, the fact that L-NAME abrogated the protective effect of simvastatin against the reperfusion-induced VF suggests that this action depends more on NO bioavailability than the ischaemiainduced VF (discussed this by Gonczi et al., 2009). Considering the electrophysiological differences between the ischaemia-induced and the reperfusion-induced arrhythmias (Wit and Janse, 2001), and that, in this latter, the products of the oxidative stress and the calcium overload (Opie and Coetzee, 1988) play a mandatory role, it seems more than likely that simvastatin through an NO-dependent way (Di Napoli et al., 2001) reduces superoxide production and hence the occurrence of VF during reperfusion. Consequently, this protection disappears by inhibiting the formation of NO.

In summary, the present study provides evidence that even a single bolus injection of simvastatin results in marked protection against those severe, often fatal ventricular arrhythmias that occur during the acute phase of the coronary artery occlusion and reperfusion in the canine. We suggest that this protection may result from both NO-dependent and NO-independent mechanisms. First, it seems that simvastatin prevents the ischaemia-induced reduction of eNOS activation; i.e. compared with controls, in dogs given simvastatin the activity of this enzyme is well preserved or even increased during a $25 \mathrm{~min}$ coronary artery occlusion and reperfusion. This would result in an enhanced NO synthesis and bioavailability during ischaemia and subsequently a reduced free radical formation during reperfusion. These NO-dependent mechanisms largely contribute to the anti-ischaemic and antiarrhythmic effects of simvastatin, since most of these beneficial effects are attenuated or abolished if the L-arginine-NO synthesis pathway was inhibited by L-NAME. Second, the fact that the protective effect of simvastatin against the occlusion-induced ventricular fibrillation was not L-NAME sensitive has raised the possibility of a direct and presumably NO-independent mechanism in the anti-arrhythmic effect of simvastatin. The measurement of QTc intervals confirms this assumption, but it does not allow speculating on mechanisms through which this direct anti-arrhythmic (antifibrillatory) effect of simvastatin would attain. This certainly warrants further cellular electrophysiological investigations.

\section{Acknowledgements}

This work was supported by the Hungarian Scientific Research Foundation (OTKA; Project number K105252). We are also grateful to the excellent technical assistance of Erika Bakó and Irene Biczók. 


\section{References}

Adameová, A., Harcárová, A., Matejiková, J., Pancza, D., Kuzelová, M., Čarnická, S. Švec, P., Barteková, M., Styk, J., Ravingerová, T., 2009. Simvastatin alleviates myocardial contractile dysfunction and lethal ischemic injury in rat heart independent of cholesterol-lowering effects. Physiol. Res. 58, 449-454.

Atar, S., Ye, Y., Lin, Y., Freeberg, S.Y., Nishi, S.P., Rosanio, S., Huang, M.H., Uretsky, B.F., Perez-Polo, J.R., Birnbaum, Y., 2006. Atorvastatin-induced cardioprotection is mediated by increasing inducible nitric oxide synthase and consequent Snitrosylation of cyclooxygenase-2. Am. J. Physiol. Heart Circ. Physiol 290, H1960-H1968.

Babai, L., Szigeti, Z.s., Parratt, J.R., Végh, Á., 2002. Delayed cardioprotective effects of exercise in dogs are aminoguanidine sensitive: possible involvement of nitric oxide. Clin. Sci. 102, 435-445.

Beri, A., Contractor, T., Khasnis, A., Thakur, R., 2010. Statins and the reduction of sudden cardiac death. Antiarrhythmic or anti-ischemic effect? Am. J. Cardiovasc. Drugs 10, 156-164.

Billman, G.E., Hallaq, H., Leaf, A., 1994. Prevention of ischemia-induced ventricular fibrillation by omega 3 fatty acids. Proc. Natl. Acad. Sci. USA 91, 4427-4430.

Birnbaum, Y., Ye, Y., Rosario, S., Tavackopli, S., Hu, Z., Schwartz, E.R., 2005. Prostaglandins mediate the cardioprotective effects of atorvastatin against ischemia-reperfusion injury. Cardiovasc. Res. 65, 345-355.

Bloom, H.L., Shukrullah, I., Veledar, E., Gutmann, R., London, B., Dudley, S.C., 2010. Statins decrease oxidative stress and ICD therapies. Card. Res. Pract. 2010, 253803.

Calabro, P., Yeh, E.T., 2005. The pleiotropic effects of statins. Curr. Opin. Cardiol. 20, 541-546.

Carnická, S., Adameová, A., Nemceková, M., Matejiková, J., Pancza, D., Ravingerová, T, 2011. Distinct effects of acute pre-treatment of with lipophilic and hydrophilic statins on myocardial stunning, arrhythmias and lethal injury in the rat heart subjected to ischemia/reperfusion. Physiol. Res. 60, 825-830.

Ceylan, A., Karasu, C., Aktan, F., Güven, C., Can, B., Ozansov, G., 2003. Effects of simvastatin treatment on oxidant/antioxidant state and ultrastructure of diabetic rat myocardium. Gen. Physiol. Biophys. 22, 535-547.

Chen, C.C., Lien, H.Y., Hsu, Y.J., Lin, C.C., Shih, C.M., Lee, T.M., 2010. Effect of pravastatin on ventricular arrhythmias in infracted rats: role of connexin 43. J. Appl. Physiol. 109, 541-552.

Chen, J., Nagasawa, Y., Zhu, B.-M., Ohmori, M., Harada, K., Fujimura, A., Hashimoto, K., 2003. Pravastatin prevents arrhythmias induced by coronary artery ische$\mathrm{mia} /$ reperfusion in anesthetized normocholesterolemic rats. J. Pharmacol. Sci. 93, 87-94.

De Sutter, J., Tavernier, R., De Buyzere, M., Jordaens, L., De Backer, G., 2000. Lipid lowering drugs and recurrences of life-threatening ventricular arrhythmias in high-risk patients. J. Am. Coll. Cardiol. 36, 766-772.

Di Napoli, P., Taccardi, A.A., Grilli, A., Spina, R., Felaco, M., Barsotti, A., De Caterina, R., 2001. Simvastatin reduces reperfusion injury by modulating nitric oxide synthase expression: an ex vivo study in isolated working rat hearts. Cardiovasc. Res. 51, 283-293.

Endres, M., 2006. Statins: potential new indications in inflammatory conditions. Atheroscler. Suppl. 7, 30-35.

Fonarow, G.C., Wright, R.S., Spencer, F.A., Fredrick, P.D., Dong, W., Every, N., French, W.J., 2005. Effect of statin use within the first $24 \mathrm{~h}$ of admission for acute myocardial infarction on early morbidity and mortality. Am. J. Cardiol. 96, 611-616.

Gould, A.L., Davies, G.M., Alemao, E., Yin, D.D., Cook., J.R., 2007. Cholesterol reduction yields clinical benefits: meta-analysis including recent trials. Clin. Ther. 29, 778-794.

Gonczi, M., Kovács, M., Seprényi, G.y., Végh, Á., 2012. The involvement of gap junctions in the delayed phase of the protection induced by cardiac pacing in dogs. Clin. Sci. 123, 39-51.

Gonczi, M., Papp, R., Kovács, M., Seprényi, G., Végh, Á., 2009. Modulation of gap junctions by nitric oxide contributes to the anti-arrhythmic effect of sodium nitroprusside. Br. J. Pharmacol. 156, 786-793.

Gyorgy, K., Végh, Á., Rastegar, M.A., Papp, J.G.y., Parratt, J.R., 2000. Isosorbide-2mononitrate reduces the consequences of myocardial ischaemia, including arrhythmia severity: implications for preconditioning. Cardiovasc. Drugs Ther. 14, 481-488.

Horwich, T.B., MacLellan, W.R., Fonarow, G.C., 2004. Statin therapy is associated with improved survival in ischemic and non-ischemic heart failure. J. Am. Coll. Cardiol. 43, 642-648.

Iwase, H., Robin, E., Guzy, R.D., Mungai, P.,T., Vanden Hoek, T.L., Chandel, N.S. Levraut, J., Schumacker, P.T., 2007. Nitric oxide during ischemia attenuates oxidant stress and cell death during ischemia and reperfusion in cardiomyocytes. Free Radic. Biol. Med. 43, 590-599.

Jones, S.P., Teshima, Y., Akao, M., Marbán, E., 2003. Simvastatin attenuates oxidantinduced mitochondrial dysfunction in cardiac myocytes. Circ. Res. 93, 697-699.

Kang, J.X., Leaf, A., 2000. Prevention of fatal cardiac arrhythmias by polyunsaturated fatty acids ${ }^{1-3}$. Am. J. Clin. Nutr. 71 (suppl), 202S-207S.

Kayikcioglu, M., Can, L., Evrengui, H., Payzin, S., Kultursay, H., 2003. The effect of statin therapy on ventricular late potentials in acute myocardial infarction. Int. J. Cardiol. 90, 63-72.

Kis, A., Végh, Á., Papp, J.G., Parratt, J.R., 1999. Repeated cardiac pacing extends the time during which canine hearts are protected against ischaemia-induced arrhythmias: role of nitric oxide. J. Mol. Cell. Cardiol. 31, 1229-1241.
Kiss, A., Juhász, L., Seprényi, G., Kupai, K., Kaszaki, J., Végh, Á., 2010. The role of nitric oxide, superoxide and peroxynitrite in the anti-arrhythmic effects of preconditioning and peroxynitrite infusion in anaesthetized dogs. Br. J. Pharmacol. 160, 1263-1272.

Kostapanos, M.S., Liberopoulos, E.N., Goudevenos, J.A., Mikhailidis, D.P., Elisaf, M.S., 2007. Do statins have an antiarrhythmic activity? Cardiovasc. Res. 75, 10-20.

Kovács, M., Gonczi, M., Kovács, E., Végh, Á., 2013. Time course analysis of cardiac pacing-induced gene expression changes in the canine heart. Mol. Cell. Biochem. 372, 257-266.

Landmesser, U., Engberding, N., Bahlmann, F.H., Schaefer, A., Wiencke, A., Heineke, A. Spiekermann, S., Hilfiker-Kleiner, D., Templin, C., Kotlarz, D., Mueller, M., Fuchs, M., Hornig, B., Haller, H., Drexler, H., 2004. Statin-induced improvement of endothelial progenitor cell mobilization, myocardial revascularization, left ventricular function, and survival after experimental myocardial infarction requires endothelial nitric oxide synthase. Circulation 110, 1933-1939.

Laufs, U., Fata, V.L., Liao, J.K., 1997. Inhibition of 3-hydroxy-3-methylglutaryl (HMG)-CoA reductase blocks hypoxia-mediated down-regulation of endothelial nitric oxide synthase. J. Biol. Chem. 272, 31725-31729.

Laufs, U., Liao, J.K., 1998. Post-transcriptional regulation of endothelial nitric oxide synthase mRNA stability by Rho GTPase. J. Biol. Chem. 273, 24266-24271.

Leaf, A., Xiao, Y.-F., Kang, J.X., Billman, G.E., 2003. Prevention of sudden cardiac death by n-3 polyunsaturated fatty acids. Pharmacol. Ther. 98, 355-377.

Lee, T.S., Chang, C.C., Zhu, Y., Shry, J., 2004. Simvastatin induces heme oxygenase-1. Circulation 110, 1296-1302.

Lefer, A.M., Campbell, B., Shin, Y.K., Scalia, R., Hayward, R., Lefer, D.J., 1999. Simvastatin preserves the ischemic-reperfused myocardium in normocholesterolemic rat hearts. Circulation 100, 178-184.

Lefer, A.M., Scalia, R., Lefer, D.J., 2001. Vascular effects of HMG CoA-reductase inhibitors (statins) unrelated to cholesterol lowering. New concepts for cardiovascular disease. Cardiovasc. Res, 49, 281-287.

Liao, J.K., Laufs, U., 2005. Pleiotropic effects of statins. Ann. Rev. Pharmacol. Toxicol. 45, 89-118.

Maguy, A., Hebert, T.E., Nattel, S., 2006. Involvement of lipid rafts and caveolae in cardiac ion channel function. Cardiovasc. Res. 69, 798-807.

Mital, S., Zhang, X., Zhao, G., Bernstein, R.D., Smith, C.J., Fulton, D.L., Sessa, W.C., Liao, J.K., Hintze, T.H., 2000. Simvastatin up regulates coronary vascular endothelial nitric oxide production in conscious dogs. Am. J. Physiol. Heart Circ. Physiol. 279, H2649-2457.

O'Driscoll, G., Green, D., Taylor, R.R., 1997. Simvastatin, an HMG-Coenzyme A reductase inhibitor, improves endothelial function within 1 month. Circulation 95, 1126-1131.

Opie, L.H., Coetzee, W.A., 1988. Role of calcium ions in reperfusion arrhythmias: relevance to pharmacologic intervention. Cardiovasc. Drugs Ther. 2, 623-636.

Parratt, J.R., Végh, Á., 1996. Endothelial cells, nitric oxide and ischaemic preconditioning. Basic Res. Cardiol. 91, 27-30.

Scandinavian Simvastatin Survival Study Group, 1994. Randomised trial of cholesterol lowering in 4444 patients with coronary artery disease: the Scandinavian Simvastatin Survival Study (4S). Lancet 344, 1383-1389.

Schwartz, P.J., Diem, R., Dun, N.J., Forstermann, U., 1995. Endogenous and exogenous nitric oxide inhibits norepinephrine release from rat heart sympathetic nerves. Circ. Res. 77, 841-848.

Shimizu, K., Aikawa, M., Takayama, K., Libbi, P., Mitchell, R.N., 2003. Direct antiinflammatory mechanisms contribute to attenuation of experimental allograft arteriosclerosis by statins. Circulation 108, 2113-2120.

Sicouri, S., Gianetti, B., Zygmunt, A.C., Cordeiro, J.M., Antzelevitch, C., 2011. Antiarrhythmic effects of simvastatin in canine pulmonary vein sleeve preparations. J. Am. Coll. Cardiol.. 57, 986-993.

Su, F., Shi, M., Yan, Z., Ou, D., Li, J., Lu, Z., Zheng, Q., 2012. Simvastatin modulates remodelling of Kv4.3 expression in rat hypertrophied cadiomyocytes. Int. J. Biol. Sci. 8, 236-248.

Szárszoi, O., Maly, J. Ostadal, P. Netuka, L., Besik, J., Kolar, F., Ostadal, B., 2008. Effect of acute and chronic simvastatin treatment on post-ischemic contractile dysfunction in isolated rat heart. Physiol. Res. 57, 793-796.

Tang, Q., Huang, J., Qian, H., Chen, L., Wang, T., Wang, H., Shen, D., Wu, H., Xiong, R., 2007. Antiarrhythmic effect of atorvastatin on autoimmune myocarditis is mediated by improving myocardial repolarization. Life Sci. 80, 601-608.

Tekin, A., Tekin, G., Sezgin, A.T., Müderrisoglu, H., 2008. Short and long-term effect of simvastatin therapy on the heterogeneity of cardiac repolarization in diabetic patients. Pharmacol. Res. 57, 393-397.

Tiefenbacher, C.P., Kapitza, J., Dietz, V., Lee, C.H., Niroomand, F., 2003. Reduction of myocardial infarct size by fluvastatin. Am. J. Physiol. Heart Circ. Physiol 285, H59-H64.

The Long-Term Intervention with Pravastatin in Ischaemic Disease (LIPID) Study Group, 1998. Prevention of cardiovascular events and death with pravastatin in patients with coronary heart disease and a broad range of initial cholesterol levels. N. Engl. J. Med. 339, 1349-1357.

Végh, Á., Komori, S., Szekeres, L., Parratt, J.R., 1992a. Antiarrhythmic effects of preconditioning in anaesthetised dogs and rats. Cardiovasc. Res. 26, 487-495.

Végh, Á., Szekeres., L., Parratt, J.R., 1992b. Preconditioning of the ischaemic myocardium; involvement of the L-arginine nitric oxide pathway. $\mathrm{Br}$. J. Pharmacol. 107, 648-652.

Vyas, A.K., Guo, H., Moss, A.J., Olshansky, B., McNitt, S.A., Hall, W.J., Zareba, W., Staiberg, J.S., Fischer, A., Ruskin, J., Andrews, M.I., 2006. for the MADIT-II Research Group, 2006. Reduction in ventricular tachyarrhythmias with statins in the Multicenter Automatic Defibrillator Implantation Trial (MADIT)-II. J. Am. Coll. Cardiol. 47, 769-773. 
Walker, M.J.A., Curtis, M.J., Hearse, D.J., Campbell, R.W.F., Janse, M.J., Yellon, D.M., Cobbe, S.M., Coker, S.J., Harness, J.B., Harron, D.W.G., Higgins, A.J., Julian, D.G., Lab, M.J., Manning, A.S., Northover, B.J., Parratt, J.R., Riemersma, R.A., Riva, E., Russell, D.C., Sheridan, D.J., Winslow, E., Woodward, B., 1988. The Lambeth Conventions: guidelines for the study of arrhythmias in ischaemia, infarction, and reperfusion. Cardiovasc. Res. 22, 447-455.

Wit, A.L., Janse, M.J., 1992. Experimental models of ventricular tachycardia and fibrillation caused by ischemia and infarction. Circulation 85 (S1), 132-142.

Wit, A.L., Janse, M.J., 2001. Reperfusion arrhythmias and sudden cardiac death: a century of progress towards an understanding of the mechanisms. Circ. Res. 89, $741-743$.

Wolfrum, S., Dendorfer, A., Schutt, M., Weidtmann, B., Heep, A., Tempel, K., Klein, H.H., Dominiak, G., Richardt, G., 2004. Simvastatin acutely reduces myocardial reperfusion injury in vivo by activating the phosphatidylinositide 3-kinase/Akt pathway. J. Cardiovasc. Pharmacol. 44, 348-355.

Wright, D.G., Lefer, D.J., 2005. Statin mediated protection of the ischemic myocardium. Vasc. Pharmacol. 42, 265-270.

Xing, D., Murry, D.J., Schmidt, M.S., Hohl, R.J., Martins, J.B., 2007. Lovastatin specifically prevents focal ischemic ventricular tachycardia due to triggered activity. Heart Rhythm 4, 629-637.

Zipes, D.P., Wellens, H.J., 1998. Sudden cardiac death. Circulation 98, 2334-2351.

Zhao, J.L., Yang, Y.J., Pei, W.D., Sun, Y.H., Chen, J.L., Gao, R.L., 2008. Effect of statin therapy on reperfusion arrhythmia in patients who underwent successful primary angioplasty. Clin. Res. Cardiol. 97, 147-151. 